\title{
Measuring Peak Inspiratory Flow in Patients with Chronic Obstructive Pulmonary Disease
}

\author{
Jill A Ohar, ID ' Gary T Ferguson, ${ }^{2}$ \\ Donald A Mahler, iD ${ }^{3}$ \\ M Bradley Drummond, (D) 4 \\ Rajiv Dhand, (ID ${ }^{5}$ Roy A Pleasants, 4,6 \\ Antonio Anzueto, ${ }^{7}$ \\ David MG Halpin, (D) ${ }^{8}$ \\ David B Price, iD 9,10 \\ Gail S Drescher, ' Haley M Hoy, ${ }^{12}$ \\ John Haughney, (iD) ${ }^{9}$ \\ Michael W Hess, ${ }^{13}$ \\ Omar S Usmani (iD) 14
}

'Section of Pulmonary, Critical Care, Allergy, and Immunology, School of Medicine, Wake

Forest University, Winston-Salem, NC, USA; ${ }^{2}$ Pulmonary Research Institute of Southeast Michigan, Farmington Hills, MI, USA; ${ }^{3}$ Geisel School of Medicine at Dartmouth, Hanover, $\mathrm{NH}, \mathrm{USA} ;{ }^{4}$ Division of Pulmonary Diseases and Critical Care Medicine, University of North Carolina at Chapel Hill, Chapel Hill, NC, USA; ${ }^{5}$ Division of Pulmonary and Critical Care Medicine, Department of Medicine, University of Tennessee Graduate School of Medicine, Knoxville, TN, USA; ${ }^{6}$ Department of Quality, University of Michigan, Ann Arbor, MI, USA; ${ }^{7}$ Pulmonology Section, University of Texas Health, and South Texas Veterans Health Care System, San Antonio, TX, USA;

${ }^{8}$ University of Exeter Medical School, College of Medicine and Health, University of Exeter,

Exeter, UK; ${ }^{9}$ Academic Primary Care,

Division of Applied Health Sciences,

University of Aberdeen, Aberdeen, UK;

${ }^{10}$ Observational and Pragmatic Research

Institute, Singapore; "'Pulmonary Services

Department, MedStar Washington Hospital

Center, Washington, DC, USA; ${ }^{2}$ Transplant

Center, Vanderbilt University Medical Center, Nashville, TN, USA: ${ }^{13}$ COPD Foundation,

Kalamazoo, MI, USA; ${ }^{14}$ National Heart and

Lung Institute, Imperial College London and

Royal Brompton Hospital, London, UK

Correspondence: jill A Ohar

Section of Pulmonary, Critical Care, Allergy, and Immunology, School of Medicine, Wake Forest University, I834 Wake Forest Road, Winston-Salem, NC 27109, USA

Tel + | 336-7| 6-8426

$\mathrm{Fax}+\mid$ 336-7|6-7277

Email johar@wakehealth.edu
Abstract: Dry powder inhalers (DPIs) are breath actuated, and patients using DPIs need to generate an optimal inspiratory flow during the inhalation maneuver for effective drug delivery to the lungs. However, practical and standardized recommendations for measuring peak inspiratory flow (PIF) - a potential indicator for effective DPI use in chronic obstructive pulmonary disease (COPD) - are lacking. To evaluate recommended PIF assessment approaches, we reviewed the Instructions for Use of the In-Check ${ }^{\mathrm{TM}}$ DIAL and the prescribing information for eight DPIs approved for use in the treatment of COPD in the United States. To evaluate applied PIF assessment approaches, we conducted a PubMed search from inception to August 31, 2021, for reports of clinical and real-life studies where PIF was measured using the In-Check ${ }^{\mathrm{TM}}$ DIAL or through a DPI in patients with COPD. Evaluation of collective sources, including 47 applicable studies, showed that instructions related to the positioning of the patient with their DPI, instructions for exhalation before the inhalation maneuver, the inhalation maneuver itself, and post-inhalation breath-hold times varied, and in many instances, appeared vague and/or incomplete. We observed considerable variation in how PIF was measured in clinical and real-life studies, underscoring the need for a standardized method of PIF measurement. Standardization of technique will facilitate comparisons among studies. Based on these findings and our clinical and research experience, we propose specific recommendations for PIF measurement to standardize the process and better ensure accurate and reliable PIF values in clinical trials and in daily clinical practice.

Keywords: chronic obstructive pulmonary disease, dry powder inhalers, peak inspiratory flow

\section{Plain Language Summary}

Chronic obstructive pulmonary disease (COPD) is a lung condition associated with cough and breathlessness, which worsens over time. COPD treatment includes inhaled medicines that can be given using pressurized metered-dose inhalers (pMDIs) or by dry powder inhalers (DPIs). The basic difference between pMDIs and DPIs is how the medicine gets to the lungs. pMDIs use a propellant to deliver the medicine into the airways, while DPIs do not contain propellants. DPIs need considerable patient effort while breathing, and each DPI has different internal resistance and breathing method. Peak inspiratory flow (PIF) measures the maximum amount of air that can be inhaled during one deep breath and is an important measure of effective DPI use. Suboptimal PIF is common and occurs in the most vulnerable COPD patients. The In-Check ${ }^{\mathrm{TM}}$ DIAL measures PIF for DPIs. There is lack of guidance for measuring PIF; we reviewed the Instructions for Use of the In-Check ${ }^{\mathrm{TM}}$ DIAL, prescribing information for eight approved DPIs, and evidence from 47 studies. 
We found differences in instructions related to DPI use and large differences in how PIF was measured in clinical versus real-world application studies. Differences in measurement may affect PIF results and standardization of methods will help to distinguish optimal versus suboptimal PIF. Exhaling fully, as recommended by most instruction manuals, is a challenge for COPD patients, leading to possible complications. Based on these findings and our clinical and research experience, we propose that patients breathe out slowly and fully to avoid fatigue and help recover from complications.

\section{Introduction}

Inhaled medications for chronic obstructive pulmonary disease (COPD) can be administered using a pressurized metered-dose inhaler (pMDI), soft-mist inhaler (SMI), nebulizer, or dry powder inhaler (DPI). ${ }^{1}$ Each inhalation device is unique and has associated advantages and disadvantages. ${ }^{2,3}$ pMDIs deliver a fixed drug dose as aerosol droplets from a pressurized canister and require coordination between inhalation and actuation, which can be challenging for some patients and may lead to reduced drug deposition in the lungs. ${ }^{4}$ The SMI generates a slowmoving aerosol cloud from an aqueous drug solution using mechanical energy. The slow-moving aerosol provides more time for better inhalation-actuation coordination, which may enhance drug delivery. ${ }^{5}$ However, some patients may find loading the cartridge into the inhaler challenging. ${ }^{2}$ Nebulizers use an external power source to generate a continuous aerosol from a liquid drug formulation and require minimal coordination and effort during inhalation; however, most nebulizers are bulky, time consuming to use, and need cleaning after use. ${ }^{6}$ Furthermore, the drug formulation (viscosity and surface tension) may influence aerosol production. ${ }^{6}$ DPIs depend on the patient's inspiratory flow (IF) to deaggregate drug and carrier particles and to disperse and deliver the aerosolized drug into the lungs. ${ }^{2,4}$ Unlike pMDIs and SMIs, which have minimal internal resistance, each DPI has a unique internal resistance and requires unique inhalation maneuvers. $^{2,3}$ Furthermore, patients may struggle to remember directions associated with different inhaler types. $^{7}$

DPIs are breath actuated and, unlike most pMDIs and the SMI, rely on the patient's IF through a resistor during the inhalation maneuver. ${ }^{3}$ Peak inspiratory flow (PIF) is defined as the maximal airflow (liters per minute) achieved during a forced inspiratory maneuver. ${ }^{8,9}$ Patients' inspiratory effort depends on their respiratory muscle strength and the lung volume from which they initiate the inhalation (functional residual capacity [FRC], residual volume [RV], or somewhere in between). ${ }^{10-12}$ The patient's inspiratory effort produces a pressure drop that determines the IF, depending on the inhaler's specific internal resistance. $^{11}$ Effective use of a DPI will depend on the patients' IF (optimal PIF is preferred) as well as the turbulence generated by the specific internal resistance of the DPI. ${ }^{1,10}$ Sufficient effort, pressure drop, and consequent PIF are needed for effective release of the dry powder from the capsule, blister pack, or reservoir; disaggregation of drug-carrier agglomerates; and optimal dispersal and deposition of respirable drug particles $(<5 \mu \mathrm{m}$ in mass median aerodynamic diameter) into the lower airways. ${ }^{8,10,11,13}$ Other factors that affect optimal drug delivery with DPIs include incorrect inhaler preparation, ${ }^{14}$ poor clinical status, ${ }^{15}$ and-because of the powder formulation - a humid environment. ${ }^{14,16}$

Internal resistances vary substantially across DPIs; therefore, the degree of flow and force needed on behalf of the patient for effective drug dispersal and lung deposition also varies. " 17 "Optimal" PIF is the IF needed to generate a high fine-particle fraction, which enables an adequate proportion of the total drug (fine particle $[1-5 \mu \mathrm{m}]$ dose) to be delivered throughout the lungs. ${ }^{8,10,18}$ A PIF of $<60 \mathrm{~L} / \mathrm{min}$ is generally considered to be suboptimal (below the optimal threshold for the inhaler) for most DPIs; ;,9,10 however, "optimal" PIFs ranging from 30 to $65 \mathrm{~L} / \mathrm{min}$ have been reported for different DPIs depending on each DPI's unique internal resistance. ${ }^{19}$

A "suboptimal" PIF can result in inadequate drugcarrier disaggregation and insufficient drug deposition deep in the airways, ${ }^{8}$ which can lead to side effects from oropharyngeal deposition. ${ }^{19}$ In some studies, older age, ${ }^{20}$ female sex, ${ }^{8,21}$ short stature, ${ }^{20,21}$ and low forced vital capacity $(\mathrm{FVC})^{20,21}$ and inspiratory capacity ${ }^{20,21}$ were associated with low PIFs. However, other studies have not shown any association between age, ${ }^{8,22}$ sex, $^{22}$ height, ${ }^{22,23}$ or $\mathrm{FVC}^{8,20}$ and PIF. Inspiratory muscle weakness, hyperinflation, concurrent exacerbation, or cachexia may also decrease PIF. ${ }^{15,23-25}$ The patient's clinical status should be considered when measuring PIF $^{10}$ — if a minimal value is chosen when the patient is clinically stable, exacerbations may lead to a below minimally acceptable PIF.

Given that multiple patient and clinical factors can potentially impact PIF, direct measurement is necessary to confirm that patients are able to optimally use the selected DPI. ${ }^{18}$ Although inhalation parameters can be measured using 
spirometry, assessment of PIF using conventional spirometry does not account for the internal resistance of $\mathrm{DPIs}^{26}$ and, thus, does not directly determine a patient's ability to generate the device-specific PIF required. ${ }^{27}$ The In-Check ${ }^{\mathrm{TM}}$ DIAL inspiratory flow meter, however, is a device that can be used to assess PIF against the simulated internal resistance of a specific DPI: ${ }^{28,29}$ no (R0), low (R1), medium low (R2), medium (R3), medium high (R4), or high (R5) resistance ${ }^{8}$ (Table 1; https://editage.sharefile.com/share/view/ s744a7fee41d149bf9f345fd8d59291a7). Results from measurements obtained using the device indicate whether a patient can achieve the optimal PIF for the selected DPI and can be helpful in guiding patients' inspiratory effort for the specific DPI. ${ }^{29-31}$ However, all clinicians-especially those in developing countries - may not have access to the In-Check ${ }^{\mathrm{TM}}$ DIAL. ${ }^{26}$ In addition to the In-Check ${ }^{\mathrm{TM}}$ DIAL, other measurement devices (attachments for DPIs or built-in devices) are in development or available to determine inhalation parameters through DPIs (Supplementary Methods). Alternatively, PIF can be measured using an inhalation profile recorder. ${ }^{32-35}$

PIF is a potential indicator for effective DPI use $;{ }^{9}$ however, the approach for measuring PIF is not standardized. Therefore, an accurate assessment of the prevalence of suboptimal PIF and its impact on clinical outcomes cannot be ascertained. Variables in PIF assessment include the device used for assessment, instructions for exhalation before inhalation (eg, from $\mathrm{RV}$; after forced expiration or slow exhalation vs FRC; after passive end-tidal expiration), number of resistance settings tested, physical position of the patient with the inhaler, and PIF calculation (one measurement vs average of multiple measurements vs best of multiple measurements). Notably, the intensity of inspiratory effort (eg, "sharp," "quick," "maximal," "forceful," and "full") differs based on patients' perceptions and varies for each inhaler according to the respective Instructions for Use. For example, a "sharp, maximal" effort will produce a different PIF versus a "full, deep" breath.

Herein, we describe findings from a systematic evaluation of recommended and applied PIF assessment approaches and, accordingly, propose a practical and standardized method of PIF measurement.

\section{Methods}

\section{Consensus Development}

An international panel of experts was convened under the leadership of J.A.O., D.A.M., G.T.F., and O.S.U. We agreed that a standardized approach to measuring PIF in
Table I Inhaler Classification Based on Internal Resistance $8,29,95,96$

\begin{tabular}{|c|c|c|}
\hline $\begin{array}{l}\text { Inhaler } \\
\text { Resistance }\end{array}$ & $\begin{array}{l}\text { Resistance } \\
\text { Class of } \\
\text { Inhaler }\end{array}$ & Inhalers \\
\hline Zero & Ro & Multiple pMDls \\
\hline Zero & Ro & Respimat $^{\circledR}(\mathrm{SMI})$ \\
\hline Low & $\mathrm{RI}$ & $\begin{array}{l}\text { Breezhaler }^{\circledR}\left(\text { Neohaler }^{\circledR a} \text { in the }\right. \\
\text { United States) }\end{array}$ \\
\hline $\begin{array}{l}\text { Medium } \\
\text { low }\end{array}$ & R2 & Accuhaler $^{\circledR} /$ Diskus $^{\circledR a}$ \\
\hline $\begin{array}{l}\text { Medium } \\
\text { low }\end{array}$ & R2 & Diskhaler $^{\circledR}$ \\
\hline $\begin{array}{l}\text { Medium } \\
\text { low }\end{array}$ & R2 & Ellipta $^{\circledR a}$ \\
\hline $\begin{array}{l}\text { Medium } \\
\text { low }\end{array}$ & R2 & $\operatorname{Inhub}^{\circledR}$ \\
\hline Medium & R3 & $\begin{array}{l}\text { Genuair }^{\circledR}\left(\text { Pressair }^{\circledR a} \text { in the }\right. \\
\text { United States) }\end{array}$ \\
\hline Medium & R3 & $\begin{array}{l}\text { Spiromax }^{\circledR} \text { (RespiClick }{ }^{\circledR a} \text { in the } \\
\text { United States)/Digihaler }{ }^{T M}\end{array}$ \\
\hline Medium & R3 & Clickhaler ${ }^{\mathrm{TM}}$ \\
\hline Medium & R3 & Turbuhaler $^{\circledR}\left(\right.$ Symbicort $\left.^{\circledR}\right)$ \\
\hline $\begin{array}{l}\text { Medium } \\
\text { high }\end{array}$ & R4 & $\begin{array}{l}\text { Turbuhaler }^{\circledR} \text { (Pulmicort } \\
\text { TM }) \\
\text { (Flexhaler }{ }^{\circledR} \text { in the United States) }\end{array}$ \\
\hline $\begin{array}{l}\text { Medium } \\
\text { high }\end{array}$ & R4 & Easyhaler ${ }^{\circledR} \mathrm{C}$ (combination) \\
\hline $\begin{array}{l}\text { Medium } \\
\text { high }\end{array}$ & R4 & Twisthaler $^{\circledR}$ \\
\hline $\begin{array}{l}\text { Medium } \\
\text { high }\end{array}$ & R4 & NEXThaler ${ }^{\circledR}$ \\
\hline High & R5 & Easyhaler ${ }^{\circledR} \mathrm{M}$ (monotherapy) \\
\hline High & R5 & HandiHaler ${ }^{\circledR a}$ \\
\hline
\end{tabular}

Note: alncluded in the present analysis.

Abbreviations: pMDI, pressurized metered-dose inhaler; SMI, soft-mist inhaler.

clinical trials and daily clinical practice was needed and posed the following three questions that needed to be addressed: (1) How should patients and the PIF assessment device be positioned during assessment?, (2) How should patients be instructed to exhale before assessment?, and (3) How should patients be instructed to inhale during assessment? We devised an approach to collect relevant information from published sources (Instructions for Use of In-Check ${ }^{\mathrm{TM}}$ DIALs and applicable DPIs, as well as 
published literature), reviewed the information, and drafted recommendations based on the findings, as well as our clinical and research experience. Consensus on the recommendations was achieved through iterative discussion and review of available literature.

\section{In-Check ${ }^{\mathrm{TM}}$ DIAL and DPIs}

Instructions for Use of the In-Check ${ }^{\mathrm{TM}}$ DIAL and InCheck $^{\mathrm{TM}}$ DIAL G16 (Clement Clarke International Ltd., Essex, UK) for the assessment of PIF were obtained from the Instructions for Use brochures. ${ }^{30,31,36}$ Information regarding daily use of the following eight DPIs approved by the United States Food and Drug Administration (FDA) for use in the treatment of COPD ${ }^{37-39}$ and prescribed in the United States at the time of the analysis was obtained from the Instructions for Use of the respective DPIs: Diskus $^{\circledR}$ (GlaxoSmithKline, Research Triangle Park, NC, USA), ${ }^{40}$ Ellipta $^{\circledR}$ (GlaxoSmithKline, Research Triangle Park, NC, USA), ${ }^{41}$ HandiHaler $^{\circledR}$ (Boehringer Ingelheim Pharmaceuticals, Inc., Ridgefield, CT, USA), ${ }^{42}$ Neohaler $^{\circledR}$ (Sunovion Pharmaceuticals Inc., Marlborough, MA, USA), ${ }^{43}$ Pressair $^{\circledR}$ (AstraZeneca Pharmaceuticals LP, Wilmington, DE, USA), ${ }^{44}$ RespiClick $^{\circledR} \quad$ (Teva Respiratory, LLC, Horsham, PA, USA), ${ }^{45}$ Digihaler $^{\mathrm{TM}}$ (Teva Respiratory, LLC, Frazer, PA, USA), ${ }^{46}$ and Inhub ${ }^{\circledR}$ (Mylan Pharmaceuticals Inc., Morgantown, WV, USA). ${ }^{47}$

\section{Clinical and Real-Life Studies}

To identify how PIF was measured in various clinical and real-life studies, we conducted a PubMed search from inception to August 31, 2021, using the following search string: ("Peak inspiratory flow" OR PIF) AND ("dry powder inhaler" OR DPI). Search results were imported into an EndNote (Clarivate Analytics, Philadelphia, PA, USA) library. Abstracts and full texts were reviewed and independently verified by all authors. Reports of PIF measurement in patients with COPD using DPIs were used in the analysis. In addition, authors contributed reports from their personal libraries that were not captured during the PubMed search as applicable.

\section{Results}

We documented basic directions included in the Instructions for Use of the In-Check ${ }^{\mathrm{TM}}$ DIAL (Table 2), daily use sections of the Instructions for Use of the eight DPIs approved by the FDA for use in COPD (Table 3), and the methodology sections of published reports of studies where PIF was assessed among patients with
COPD using DPIs (Supplementary Table 1), as well as the thresholds for optimal and/or suboptimal PIFs from published reports of studies and the mean PIF value measured, where available (Supplementary Table 2). Instructions on how to exhale before the inhalation maneuver, the inhalation maneuver itself, and post-inhalation breath-hold varied (Tables 2, 3, and Supplementary Table 1). In many instances, instructions seemed vague and/or incomplete, and no clear guidance as to whether to measure PIF from RV or FRC was provided. Likewise, specific details regarding how PIF was measured in clinical and real-life studies were often vague, incomplete, or absent.

\section{In-Check ${ }^{\mathrm{TM}}$ DIAL}

How to assess whether a patient can achieve PIF within the clinically effective range of a particular DPI is outlined in the Instructions for Use of the In-Check ${ }^{\mathrm{TM}}$ DIAL (Table 2). ${ }^{30,36}$ A notable difference between the 2010 (InCheck $^{\mathrm{TM}}$ DIAL) and 2016 (In-Check ${ }^{\mathrm{TM}}$ DIAL G16) versions of the device is the instruction recommended by the manufacturer to "exhale slowly and deeply" (2010) versus "exhale fully" (2016) before inhalation. No additional direction is provided in either instance; however, the instructions accompanying the In-Check ${ }^{\mathrm{TM}}$ G16 more closely mimic patient instructions for most DPIs. No instruction regarding the physical position of the patient's head or body or the inhaler/In-Check ${ }^{\mathrm{TM}}$ DIAL is provided in the Instructions for Use. However, a video demonstrating the use of the In-Check ${ }^{\text {TM }}$ DIAL, which shows that the device should be held horizontally during PIF measurement after exhalation, is available on the manufacturer's website. ${ }^{31}$

\section{Prescribing Information of DPIs}

Steps for daily use of the eight DPIs are summarized in Table 3. ${ }^{40-47}$ Instructions for exhalation included "breathe out (exhale) as long as you can" (Diskus ${ }^{\circledR}$ and Inhub $\left.^{\circledR}\right) ;^{40,47}$ "breathe out (exhale) fully" (Ellipta ${ }^{\circledR}$ and Neohaler $\left.{ }^{\circledR}\right) ;{ }^{41,43}$ "breathe out completely in one breath, emptying your lungs of any air" (HandiHaler $\left.{ }^{\circledR}\right) ;{ }^{42}$ "breathe out completely" (Pressair $\left.{ }^{\mathbb{R}}\right){ }^{44}$ and breathe out (exhale) through your mouth and push as much air from your lungs as you can (RespiClick ${ }^{\circledR}$ and Digihaler ${ }^{\mathrm{TM}}$ ). ${ }^{45,46}$ Instructions for inhalation included "breathe in quickly and deeply" $\left(\right.$ Diskus $^{\circledR}$, Inhub $^{\mathrm{TM}}$, RespiClick ${ }^{\circledR}$, and DigihalerTM); ${ }^{40,45-47}$ "take a long, steady, deep breath" $\left(\right.$ Ellipta $\left.^{\circledR}\right) ;{ }^{41}$ "breathe in deeply until your lungs are full" (HandiHaler $\left.{ }^{\circledR}\right){ }^{42}$ "breathe in rapidly but steadily, as 
Table 2 Instructions for Use of the In-Check ${ }^{T M}$ DIAL

\begin{tabular}{|c|c|}
\hline In-Check ${ }^{\mathrm{TM}}$ DIA & In-Check ${ }^{\text {TM }}$ DIAL GI6 2016 \\
\hline $\begin{array}{l}\text { I. Reset the In-Check }{ }^{\mathrm{TM}} \text { DIAL: hold the instrument vertically with the } \\
\text { mouthpiece uppermost, so that the rounded end of the meter can be } \\
\text { tapped against the other hand or a horizontal surface, such as a table. } \\
\text { A gentle tap will dislodge the magnetic resetting weight, which will } \\
\text { return the red cursor to a start position. When this has happened, the } \\
\text { meter must turn through I } 80 \text { degrees to return the magnetic weight to } \\
\text { its resting position } \\
\text { 2. Align the scale with the desired inhaler device-an audible "click" } \\
\text { should be heard } \\
\text { 3. Attach a clean mouthpiece (small mouthpieces can be used with the } \\
\text { supplied adaptor) } \\
\text { 4. Ask the patient to exhale slowly and deeply } \\
\text { 5. Seal lips around the mouthpiece. According to the inhaler chosen, } \\
\text { instruct the patient to inhale in the manner recommended by } \\
\text { the manufacturer } \\
\text { 6. Record the inspiratory flow from the position of the red cursor } \\
\text { against the scale. Reset, and repeat } 2 \text { more times } \\
\text { 7. Compare values achieved with target flows for that device. To } \\
\text { operate an inhaler device optimally, the patient should be able to } \\
\text { achieve a flow rate within the optimal range. If other inhalers are used, } \\
\text { then repeat steps I to } 7\end{array}$ & $\begin{array}{l}\text { I. Reset the In-Check }{ }^{\mathrm{TM}} \text { DIAL GI6: hold the instrument vertically with } \\
\text { the mouthpiece uppermost, so that the rounded end of the meter can } \\
\text { be tapped against the other hand or a horizontal surface, such as a table. } \\
\text { A hard tap will dislodge the magnetic resetting weight, which will return } \\
\text { the red cursor to a start position } \\
\text { 2. Align the dial selector with the desired colored icon-an audible } \\
\text { "click" should be heard } \\
\text { 3. Attach a clean mouthpiece. Disposable I-way inspiratory } \\
\text { mouthpieces are preferred } \\
\text { 4. Ask the patient to exhale fully } \\
\text { 5. Ask the patient to seal their lips around the mouthpiece. According } \\
\text { to the inhaler chosen, instruct the patient to inhale in the manner } \\
\text { recommended by the manufacturer } \\
\text { 6. Record the inspiratory flow from the position of the red cursor } \\
\text { against the scale. Reset, and repeat } 2 \text { more times, ensuring correct } \\
\text { technique each time } \\
\text { 7. Compare values achieved with target flows for that device. To } \\
\text { operate an inhaler device correctly, the patient should be able to } \\
\text { achieve a flow rate within the clinically effective range (eg, Accuhaler }{ }^{\circledR} \text { : } \\
\text { clinically effective flow rate } 30-90 \text { L/min) } \\
\text { 8. If after repeated training the patient is not able to achieve these } \\
\text { values, then the healthcare professional may wish to assess the patient's } \\
\text { ability to use an alternative type of inhaler }\end{array}$ \\
\hline
\end{tabular}

Notes: Consult the Instructions for Use and manufacturer's website for cleaning/hygiene instructions. ${ }^{90}$

deeply as you can" (Neohaler $\left.{ }^{\circledR}\right) ;{ }^{43}$ and "take a strong, deep breath" (Pressair $\left.{ }^{\circledR}\right){ }^{44}$

Instructions for patients' head positioning were included for HandiHaler ${ }^{\circledR}$ ("hold your head in an upright position while you are looking straight ahead") ${ }^{42}$ and Pressair $^{\circledR}$ ("hold your head upright"). ${ }^{44}$ Instructions for patients' body positioning were not included for any other DPI. Most Instructions for Use included the following statement: The actual amount of drug delivered to the lung will depend on patient factors, such as IF profile. ${ }^{40-47}$ Instructions for inhaler positioning were provided for all DPIs.

\section{PIF in Published Studies}

Of the 128 articles retrieved, 40 were reports of studies where PIF was measured through a DPI or using the InCheck $^{\text {TM }}$ DIAL in patients with COPD. ${ }^{7,8,12,20-}$ 24,26,32,34,35,48-75 Reports of asthma studies ( $\mathrm{n}=30$ ); review articles $(\mathrm{n}=10)$; and non-English language articles, editorials, and articles involving healthy subjects or patients with other respiratory diseases; or reports from modeling/simulations $(n=48)$ were excluded. An additional seven articles were included from the authors' personal libraries; ${ }^{33,76-81}$ therefore, a total of 47 reports were included in the analysis.

PIF was measured using DPIs and/or inhalation profile recorders in 25 (53.2\%) studies and the In-Check ${ }^{\mathrm{TM}}$ DIAL or other devices in the remaining 22 (46.8\%) studies (Supplementary Table 1). In most published reports of studies where PIF was measured using the In-Check ${ }^{\mathrm{TM}}$ DIAL, thresholds for optimal and/or suboptimal PIF were reported (Supplementary Table 2).

In a few studies, patients were reportedly seated during inhalation. ${ }^{12,22,24,52,64,72}$ The position of the inhaler was reported in three studies to be vertical (Pulvinal ${ }^{\mathrm{TM}}$ and Turbuhaler $\left.^{\circledR}\right)^{62}$ or upright $\quad\left(\right.$ NEXThaler $^{70}$ and Turbuhaler $\left.{ }^{\circledR 74}\right)$. The position of the patient's head during inhalation was not reported in any study. Overall, the PIF measurement details, including inhalation instructions, were provided or participants were referred to patient information leaflets in 35 of the 47 studies $(74.5 \%$; Supplementary Table 1)..$^{7,12,21-23,26,32-34,48,51-66,68,70-}$ 72,74-76,78,79 Instructions for exhalation before the inhalation maneuver were provided in 14 (29.8\%) studies and included "exhale gently to FRC,"12,26,60,66 "complete exhalation,"21,23,57,74 "exhale to RV,"60,75 "deeply 
Table 3 Instructions for Daily Use of DPIs That Are Approved by the Food and Drug Administration for the Treatment of COPD and Currently Prescribed in the United States

\begin{tabular}{|c|c|c|}
\hline DPI (Medication) & $\begin{array}{l}\text { Inhalation Maneuver Instructions (Based on } \\
\text { Prescribing Information) }\end{array}$ & $\begin{array}{l}\text { Peak Inspiratory Flow (Range) Through Inhaler } \\
\text { as Reported in the Applicable Prescribing } \\
\text { Information }\end{array}$ \\
\hline Diskus $^{\circledR}$ (salmeterol $^{40}$ & $\begin{array}{l}\text { - Always use the Diskus }{ }^{\circledR} \text { in a level, flat position with } \\
\text { the mouthpiece toward you } \\
\text { - Before you breathe in your dose from the Diskus }{ }^{\circledR} \text {, } \\
\text { breathe out (exhale) as long as you can while you } \\
\text { hold the Diskus }{ }^{\circledR} \text { level and away from your mouth. Do } \\
\text { not breathe into the mouthpiece } \\
\text { - Put the mouthpiece to your lips. Breathe in quickly } \\
\text { and deeply through the Diskus }{ }^{\circledR} \text {. Do not breathe in } \\
\text { through your nose } \\
\text { - Remove the Diskus }{ }^{\circledR} \text { from your mouth and hold your } \\
\text { breath for about } 10 \text { seconds, or for as long as is } \\
\text { comfortable for you } \\
\text { - Breathe out slowly as long as you can }\end{array}$ & $\begin{array}{l}\text { Mean: } 82.4 \mathrm{~L} / \mathrm{min}(46 . \mathrm{I}-\mathrm{I} 15.3 \mathrm{~L} / \mathrm{min}) \text { in adult subjects } \\
\text { with obstructive lung disease and severely compromised } \\
\text { lung function (mean FEV , } 20 \%-30 \% \text { of predicted) }\end{array}$ \\
\hline $\begin{array}{l}\text { Ellipta }^{\circledR} \text { (vilanterol and } \\
\text { umeclidinium })^{41}\end{array}$ & $\begin{array}{l}\text { - While holding the inhaler away from your mouth, } \\
\text { breathe out (exhale) fully. Do not breathe out into } \\
\text { the mouthpiece } \\
\text { - Put the mouthpiece between your lips and close your } \\
\text { lips firmly around it. Your lips should fit over the curved } \\
\text { shape of the mouthpiece } \\
\text { - Take a long, steady, deep breath in through your } \\
\text { mouth. Do not breathe in through your nose } \\
\text { - Do not block the air vent with your fingers } \\
\text { - Remove the inhaler from your mouth and hold your } \\
\text { breath for about } 3 \text { to } 4 \text { seconds (or for as long as is } \\
\text { comfortable for you) } \\
\text { - Breathe out slowly and gently }\end{array}$ & $\begin{array}{l}\text { Mean: } 66.5 \mathrm{~L} / \mathrm{min}(43.5-81.0 \mathrm{~L} / \mathrm{min}) \text { in adult subjects } \\
\text { with } \mathrm{COPD} \text { with } \mathrm{FEV}_{1} / \mathrm{FVC}<70 \% \text { and } \mathrm{FEV}_{1}<30 \% \text { of } \\
\text { predicted or } \mathrm{FEV},<50 \% \text { of predicted plus chronic } \\
\text { respiratory failure }\end{array}$ \\
\hline HandiHaler ${ }^{\circledR}$ (tiotropium $)^{42}$ & $\begin{array}{l}\text { - Breathe out completely in one breath, } \\
\text { emptying your lungs of any air. Do not breathe into } \\
\text { your HandiHaler }{ }^{\circledR} \text { device } \\
\text { - Hold your head in an upright position while you are } \\
\text { looking straight ahead } \\
\text { - Raise your HandiHaler }{ }^{\circledR} \text { device to your mouth in } \\
\text { a horizontal position. Do not block the air intake vents } \\
\text { - Close your lips tightly around the mouthpiece } \\
\text { - Breathe in deeply until your lungs are full. You } \\
\text { should hear or feel the Spiriva }{ }^{\circledR} \text { capsule vibrate (rattle) } \\
\text { - Hold your breath for a few seconds and, at the same } \\
\text { time, take your HandiHaler }{ }^{\circledR} \text { device out of your mouth } \\
\text { - Breathe normally again } \\
\text { - To get your full daily dose, you must again breathe out } \\
\text { completely, and for a second time, breathe in from the } \\
\text { same Spiriva }{ }^{\circledR} \text { capsule }\end{array}$ & $\begin{array}{l}\text { Median: } 30.0 \mathrm{~L} / \mathrm{min}(20.4-45.6 \mathrm{~L} / \mathrm{min}) \text { in adult patients } \\
\text { with } \mathrm{COPD} \text { and severely compromised lung function } \\
\text { (mean } \mathrm{FEV}_{1}: \quad 1.02 \mathrm{~L} \text { [range: } 0.45-2.24 \mathrm{~L} \text { ]; } 37.6 \% \text { of } \\
\text { predicted [range: } 16 \%-65 \% \text { ]) }\end{array}$ \\
\hline
\end{tabular}

(Continued) 
Table 3 (Continued).

\begin{tabular}{|c|c|c|}
\hline DPI (Medication) & $\begin{array}{l}\text { Inhalation Maneuver Instructions (Based on } \\
\text { Prescribing Information) }\end{array}$ & $\begin{array}{l}\text { Peak Inspiratory Flow (Range) Through Inhaler } \\
\text { as Reported in the Applicable Prescribing } \\
\text { Information }\end{array}$ \\
\hline $\begin{array}{l}\text { Neohaler }^{\circledR} \text { (indacaterol and } \\
\text { glycopyrrolate) }\end{array}$ & $\begin{array}{l}\text { - Hold the inhaler as shown in the figure in the } \\
\text { prescribing information } \\
\text { - Before placing the mouthpiece in your mouth, } \\
\text { breathe out fully. Do not blow into the mouthpiece } \\
\text { - Before breathing in make sure that the piercing } \\
\text { buttons are to the left and right of the inhaler (not up } \\
\text { and down) } \\
\text { - Place the mouthpiece in your mouth and close your } \\
\text { lips firmly around the mouthpiece } \\
\text { - Breathe in rapidly but steadily, as deeply as you } \\
\text { can. Do not press the piercing buttons } \\
\text { - As you breathe in through the inhaler, the capsule } \\
\text { spins around in the chamber and you should hear } \\
\text { a whirring noise } \\
\text { - Continue to hold your breath for at least } 5 \text { to } 10 \\
\text { seconds or for as long as comfortably possible while } \\
\text { removing the inhaler from your mouth. Then breathe } \\
\text { out }\end{array}$ & $\begin{array}{l}\text { Mean: } 95 \mathrm{~L} / \mathrm{min}(52-133 \mathrm{~L} / \mathrm{min}) \text { in adult patients with } \\
\text { COPD of varying severity }\end{array}$ \\
\hline Pressair $^{\circledR}$ (aclidinium) $)^{44}$ & $\begin{array}{l}\text { - Hold the inhaler horizontally with the mouthpiece } \\
\text { facing you and the green button on top } \\
\text { - Hold the inhaler away from your mouth and breathe } \\
\text { out completely. Never breathe out into the inhaler } \\
\text { - Hold your head upright, put the mouthpiece between } \\
\text { your lips, and close your lips tightly around the } \\
\text { mouthpiece } \\
\text { - Take a strong, deep breath through your mouth. } \\
\text { Keep breathing in for as long as possible } \\
\text { - Take the inhaler out of your mouth. Hold your breath } \\
\text { for as long as possible. Slowly breathe out, away from } \\
\text { the inhaler }\end{array}$ & Mean: $63 \mathrm{~L} / \mathrm{min}$ by in vitro testing \\
\hline $\begin{array}{l}\operatorname{RespiClick}^{\circledR} \text { (albuterol } \\
\text { sulfate }^{45} \text { and Digihaler } \\
\text { (albuterol sulfate) }^{46}\end{array}$ & $\begin{array}{l}\text { - Hold the inhaler upright and open the red cap fully } \\
\text { until you feel and hear a "click" } \\
\text { - Each time you open the red cap and it "clicks", a dose } \\
\text { of ProAir RespiClick }{ }^{\circledR} / \text { Digihaler }{ }^{T M} \text { is ready to be inhaled } \\
\text { - Before you inhale, breathe out (exhale) through your } \\
\text { mouth and push as much air from your lungs as } \\
\text { you can } \\
\text { - Do not exhale into the inhaler mouthpiece } \\
\text { - Put the mouthpiece in your mouth and close your lips } \\
\text { tightly around it } \\
\text { - Do not block the vent above the mouthpiece with } \\
\text { your lips or fingers } \\
\text { - Breathe in quickly and deeply through your } \\
\text { mouth, to deliver the dose of medicine to your lungs } \\
\text { - Remove the inhaler from your mouth } \\
\text { - Hold your breath for about } 10 \text { seconds or for as long } \\
\text { as you comfortably can }\end{array}$ & Mean: $>60 \mathrm{~L} / \mathrm{min}(3 \mathrm{I}-110 \mathrm{~L} / \mathrm{min})$ \\
\hline
\end{tabular}

(Continued) 
Table 3 (Continued).

\begin{tabular}{|c|c|c|}
\hline DPI (Medication) & $\begin{array}{l}\text { Inhalation Maneuver Instructions (Based on } \\
\text { Prescribing Information) }\end{array}$ & $\begin{array}{l}\text { Peak Inspiratory Flow (Range) Through Inhaler } \\
\text { as Reported in the Applicable Prescribing } \\
\text { Information }\end{array}$ \\
\hline $\begin{array}{l}\text { Inhub }{ }^{\circledR} \text { (fluticasone } \\
\text { propionate and } \\
\text { salmeterol) }{ }^{47}\end{array}$ & $\begin{array}{l}\text { - Hold the Inhub }{ }^{\circledR} \text { in the vertical position } \\
\text { - Before you breathe in your dose from the Inhub }{ }^{\circledR} \text {, } \\
\text { breathe out (exhale) as long as you can while you } \\
\text { hold the Inhub }{ }^{\circledR} \text { away from your mouth. Do not breathe } \\
\text { into the mouthpiece } \\
\text { - Put the mouthpiece to your lips. Breathe in quickly } \\
\text { and deeply through the Inhub }{ }^{\circledR} \text {. Do not breathe in } \\
\text { through your nose } \\
\text { - Remove the Inhub } \\
\text { breath for about } 10 \text { seconds, or for as long as is } \\
\text { comfortable for you } \\
\text { - Breathe out slowly for as long as you can }\end{array}$ & $60 \mathrm{~L} / \mathrm{min}$ under standardized in vitro test conditions \\
\hline
\end{tabular}

Abbreviations: COPD, chronic obstructive pulmonary disease; DPI, dry powder inhaler; FEV , forced expiratory volume in I second; FVC, forced vital capacity.

exhale,",62 "breathe out completely,"74 and "breathe out as far as comfortable". ${ }^{70}$ In one study, PIF was measured after patients were asked to inhale as they normally do. ${ }^{49}$ In four studies, patients were asked to inhale as they did at home with their own inhaler using the In-Check ${ }^{\mathrm{TM}}$ DIAL (with the resistance set to the specific inhaler they used), ${ }^{8,61,74,81}$ and in one of these four studies, patients judged to have a weak inhalation were instructed to inhale more forcefully before another PIF measurement was taken. ${ }^{61}$

For most studies where the In-Check ${ }^{\mathrm{TM}}$ DIAL was used, resistance was set to match the internal airflow resistance of the respective inhaler(s). ${ }^{8,12,20,21,23,24,55,57,58,61,63,67,74,76,80,81}$ PIF calculation, however, varied across studies. In some studies, the highest PIF value of two ${ }^{7,49,76}$ or three ${ }^{12,20-}$ $24,33-35,48,56,57,59,63,67,72,74,75,80$ replicate inhalations per inhaler was used for analyses; in two studies, average values were reported. ${ }^{8,55}$ In other studies, the patient performed inhalation maneuvers until two consecutive PIF readings were within $20 \%$ of each other. ${ }^{26,66}$

\section{Discussion}

The ability to generate an optimal IF is essential for effective aerosol drug delivery from a DPI. ${ }^{8,18}$ Therefore, standardization of PIF measurements is critical to making uniform decisions in clinical practice. In this systematic evaluation of recommended and applied PIF assessment approaches, we observed considerable variations in the way patients were instructed to use their inhalers, as well as how PIF was measured in clinical and real-life studies.
First, the Instructions for Use for the In-Check ${ }^{\mathrm{TM}}$ DIAL lacked specific guidance regarding the positioning of the patient's head and body or inhaler. Likewise, steps for daily use of the eight analyzed DPIs varied in many respects and lacked in-depth instruction. Furthermore, instructions provided to patients during PIF assessments in clinical and real-life studies were diverse and often vague. In a few studies, instructions were in line with patient information leaflets/Instructions for Use brochures. ${ }^{7,51,53,56,59,62,68,71,72,74}$ In other studies, the instructions were not consistent with the Instructions for Use leaflet for the DPI being evaluated. ${ }^{76,79}$ The contents of the Instructions for Use of the In-Check ${ }^{\mathrm{TM}}$ DIAL were consistent with instructions provided to patients using DPIs in one study ${ }^{58}$ but not in others. ${ }^{21,23}$ In clinical studies, patients were often provided rather straightforward, but inconsistent, instructions for the inhalation maneuver; however, they were seldom clearly instructed on how to exhale beforehand. Therefore, patients were not optimally preparing for the PIF assessment.

Factors such as the position of the patient's head such that the chin is slightly upward affect drug deposition and, subsequently, outcomes in asthma. ${ }^{82}$ The effect of posture on aerosol delivery from DPIs has not been reported. However, in a study evaluating regional lung deposition using a nebulized drug (median mass aerodynamic diameter of $4.9 \mu \mathrm{m}$ ), aerosol delivery was shifted to the bronchial airways rather than the alveolar region when the drug was administered in the supine versus seated position. ${ }^{83}$ Differences in FRC and regional changes in 
ventilation accounted for these findings. We recommend that patients maintain an upright seated or erect standing position - with the chin pointed slightly upward - during the PIF assessment process.

In the Instructions for Use of the In-Check ${ }^{\mathrm{TM}}$ DIAL and DPIs and in clinical and real-life studies, the definition of "full exhalation" varied. In a large observational prospective study, the ability of patients with COPD to breathe out completely in one breath was reported to be one of the most problematic steps with inhaled medication use. ${ }^{84}$ Although exhaling completely is recommended in the Instructions for Use for most DPIs, expert opinion suggests that patients who exhale "fully and completely" (down to RV) could collapse their small airways at very low lung volumes. There are, however, no published data that support this widely held opinion other than the textbook by Bouhuys that notes that breathing at low lung volumes for prolonged periods results in atelectasis. ${ }^{85}$ Therefore, during the subsequent inhalation phase, the "energy" generated by the inhaled breath/volume must overcome the "opening" of the collapsed small airways caused by exhaling "fully and completely." The resultant energy available during inhalation to overcome airway collapse may be (not yet proven) inadequate to generate the required inspiratory acceleration and energy necessary to optimally activate the DPI. Although RV is a desirable measurement point, it is often difficult to assess and obtain. Furthermore, patients who are hospitalized or frequently ill are unable to exhale to RV. Therefore, considering these variabilities and potential challenges with complete exhalation, we recommend "breathing out slowly and fully," which is generally consistent with the Instructions for Use for DPIs and can be realistically performed by a patient in a clinical setting.

Although patients were generally provided with the actual direction about the inhalation maneuver in clinical studies, instructions varied. Patients were instructed to breathe in "rapidly/forcefully and deeply" in some studies, ${ }^{57,62,70,74,79}$ but in others, they were told to take "long/hard and fast"12,32,56,60,63,75 or "quick", breaths. The inhalation maneuver is one of the problematic steps that could potentially lead to errors with inhaled medication use, ${ }^{84}$ and its effect on drug deposition has been reported in several studies. ${ }^{8,86}$ In studies using Diskus $^{\circledR}$ and Aerolizer ${ }^{\circledR}$, a "hard and deep" inhalation resulted in higher urinary salbutamol excretion and was recommended in patients with poor inspiratory effort, such as the elderly. ${ }^{87,88}$ In a separate study, patients using indacaterol Breezhaler ${ }^{\circledR}\left(\right.$ Neohaler $\left.^{\circledR}\right)$ were instructed to "inhale as hard and fast as they can from the start of the inhalation maneuver and for as long as possible" to maximize drug delivery. ${ }^{32}$

PIF needs to be reached almost immediately (approximately 1 second) after the inhalation maneuver begins, and the achieved level of inspiration needs to be maintained during the entire inhalation maneuver (inspiratory profile) for effective drug release. A limitation of the In-Check ${ }^{\mathrm{TM}}$ Dial is that only PIF is measured, not the flow over the entire inspiratory profile or the timing in the inspiratory cycle when PIF is reached. Hence, at what time the patient is achieving PIF - in the first few seconds, when needed, or later-is not known. We recommend that patients should "inhale as fast, and as forcefully and deeply" as they can once their lips are sealed around the mouthpiece and should maintain this level of inhalation for as long as possible.

Finally, we recommend that a maximum of three consecutive measures should be used to determine the highest PIF versus the average of two or three measures; ${ }^{89}$ appropriate hygiene instructions should be followed for the InCheck $^{\mathrm{TM}}$ DIAL; ${ }^{90}$ and the decision to assess PIF should be made by the healthcare provider based on patient-level information (eg, health status) and guidance set forth by organizations such as the American Thoracic Society regarding pulmonary function testing. ${ }^{91,92}$

We aimed to provide recommendations that are aligned with real-world experience and directions for performing spirometry $^{92-94}$ so that they are useful, practical, and ultimately beneficial to patients (Table 4; https://editage.share file.com/share/view/s744a7fee41d149bf9f345fd8d59291a7). Our recommendations are largely based on the In-Check ${ }^{\mathrm{TM}}$ DIAL; recommendations for other PIF measurement devices may differ. Suboptimal PIF (ie, PIF below the optimal threshold for the selected DPI) has been widely reported, 8,12,20,23 can result in less than favorable outcomes, ${ }^{9}$ and may be associated with hospital readmissions. ${ }^{22}$ With an optimal PIF, sufficient dose of medication is more likely to be delivered, which should contribute to better clinical outcomes. Of note, however, the definition of "optimal" PIF for each individual DPI and the methods to measure PIF continue to be investigated.

Limitations to our evaluation include extrapolation from in vitro data and difficulty in providing a precise cutoff for the "suboptimal" PIF for each DPI. Findings from studies attempting to correlate suboptimal PIF with clinical outcomes were inconsistent. ${ }^{22,23}$ Furthermore, our recommendations are based on experience in clinical practice and 
Table 4 Summary of Main Recommendations

\begin{tabular}{|l|l|l|}
\hline Variables & Recommendations & Rationale \\
\hline Position & $\begin{array}{l}\text { Maintain an upright seated or erect standing position-with the } \\
\text { chin pointed slightly upward_during the PIF assessment } \\
\text { process }\end{array}$ & $\begin{array}{l}\text { Positioning the patient's head to have the chin slightly upward } \\
\text { has been shown to affect drug deposition and, subsequently, } \\
\text { outcomes in asthma }\end{array}$ \\
\hline Exhalation & Breathe out slowly and fully & $\begin{array}{l}\text { Patients who exhale "fully and completely" could cause collapse } \\
\text { of their small airways at low lung volumes. During the } \\
\text { subsequent inhalation phase, the "energy" generated by the } \\
\text { inhaled breath/volume has to overcome the "opening" of the } \\
\text { collapsed small airways that have been induced by exhaling "fully } \\
\text { and completely." The resultant energy available during inhalation } \\
\text { to overcome airway collapse may be (not yet proven) } \\
\text { inadequate to generate the required inspiratory acceleration } \\
\text { and energy necessary to optimally activate the DPI }\end{array}$ \\
\hline Inhalation & $\begin{array}{l}\text { Inhale as fast, forcefully, and deeply as you can once your lips are } \\
\text { sealed around the mouthpiece and maintain this level of } \\
\text { inhalation for as long as possible }\end{array}$ & $\begin{array}{l}\text { PIF needs to be reached almost immediately (approximately } \\
\text { I second) after the inhalation maneuver begins, and the achieved } \\
\text { level of inspiration needs to be maintained during the entire } \\
\text { inhalation maneuver (inspiratory profile) for effective drug } \\
\text { release }\end{array}$ \\
\hline
\end{tabular}

Abbreviations: DPI, dry powder inhaler; PIF, peak inspiratory flow.

require further evaluation. Studies in which the impact of different inspiratory techniques (breathing out completely vs as much as possible, sitting vs standing) on PIF measurement are lacking, and additional studies are warranted.

\section{Conclusions}

Our analysis of recommended and applied PIF assessment approaches revealed considerable variations in the way PIF is measured for the use of DPIs. Standardization of PIF measurements is needed because a patient's ability to generate an optimal IF is essential for effective drug delivery from a DPI. Based on current evidence, we recommend that while in a seated position, patients comfortably exhale slowly and fully, then inhale through the mouthpiece as fast and as forcefully and deeply as they can and maintain that level of inhalation for as long as possible. If adopted, these recommendations should yield PIF measurements that are conducted in a reproducible, standardized manner, which will help clinicians select the appropriate inhaler for each patient and, if selecting a DPI, help patients achieve the optimal PIF needed for effective drug dispersal and deposition.

\section{Abbreviations}

COPD, chronic obstructive pulmonary disease; DPI, dry powder inhaler; FDA, Food and Drug Administration; FRC, functional residual capacity; FVC, forced vital capacity; IF, inspiratory flow; PIF, peak inspiratory flow;
pMDI, pressurized metered-dose inhaler; RV, residual volume; SMI, soft-mist inhaler.

\section{Acknowledgments}

The authors meet the criteria for authorship as recommended by the International Committee of Medical Journal Editors. The authors received no direct compensation related to the development of the manuscript. Writing, editorial support, and formatting assistance was provided by Suchita NathSain, $\mathrm{PhD}$, and Maribeth Bogush, $\mathrm{PhD}$, of Cactus Life Sciences (part of Cactus Communications), which was contracted and compensated by Boehringer Ingelheim Pharmaceuticals, Inc. (BIPI) for these services. BIPI was given the opportunity to review the manuscript for medical and scientific accuracy as well as intellectual property considerations.

\section{Author Contributions}

All authors contributed to the analysis and interpretation of data and critical review of the manuscript; agreed on the journal to which the manuscript will be submitted; reviewed and agreed on all versions of the manuscript before submission, during revision and the final version accepted for publication as well as any significant changes introduced at the proofing stage; and agree to take responsibility and be accountable for the contents of the article. 


\section{Funding}

Writing, editorial support, and formatting assistance was contracted and compensated by Boehringer Ingelheim Pharmaceuticals, Inc. (BIPI).

\section{Disclosure}

J. A. O. reports personal fees from and serving on the advisory board of AstraZeneca, Mylan, Sunovion, Boehringer Ingelheim, GlaxoSmithKline, Hughes Hubbard Law Firm, Reckitt Benckiser, Teva, Theravance, and Verona, and has received grants from Sunovion for a clinical study outside the submitted work. G. T. F. reports grants, personal fees, and nonfinancial support from Boehringer Ingelheim, AstraZeneca, Novartis, Pearl Therapeutics, Sunovion, Teva, Theravance, and GlaxoSmithKline; personal fees from DevPro, Galderma, Mylan, Orpheris, Innoviva, and Circassia; grants and personal fees from Sanofi and Verona; and grants from Chiesi and Altavant outside the submitted work. D. A. M. serves on the advisory boards of AstraZeneca, Boehringer Ingelheim, GlaxoSmithKline, Mylan, Teva, Theravance, Verona, Viatris, and Sunovion; is on the speakers' bureau for AstraZeneca, Boehringer Ingelheim, and Sunovion; and received royalties from Salem Communications Holding Corporation for COPD: Answers to Your Questions, 2014. He also reports use of baseline and transition dyspnea indexes in clinical trials from several pharmaceutical companies (2020: eResearch Technology, Inc. and Parexel International; 2021: Palobiofarma S.L.; YPrime; and eResearch Tchnology, Inc.). M. B. D. reports grants and personal fees from Boehringer Ingelheim; personal fees from GlaxoSmithKline, AstraZeneca, Mylan-Theravance, Novavax, Parion, Midmark, and Philips; and grants from Teva and the Department of Defense and National Institutes of Health outside the submitted work. R. D. serves on the advisory boards of AstraZeneca, Boehringer Ingelheim, Mylan-Theravance, GlaxoSmithKline, and Bayer; reports speaker fees from Boehringer Ingelheim, Teva, and Sunovion; provides manuscript support for AstraZeneca, Boehringer Ingelheim, and Bayer; and has received honorarium from UptoDate. R. A. P. reports grants from AstraZeneca; personal fees from Theravance; and grants and personal fees from Boehringer Ingelheim and Teva. A. A. reports consulting fees from AstraZeneca, Boehringer Ingelheim, GlaxoSmithKline, Mylan-Theravance, and Teva outside the submitted work. D. M. G. H. reports personal fees from AstraZeneca, Chiesi, Novartis, Pfizer, and Sanofi; personal fees and nonfinancial support from Boehringer Ingelheim and GlaxoSmithKline outside the submitted work. D.B.P. reports advisory board membership with AstraZeneca, Boehringer Ingelheim, Chiesi, Mylan, Novartis, Regeneron Pharmaceuticals, Sanofi Genzyme, Thermofisher; consultancy agreements with Airway Vista Secretariat, AstraZeneca, Boehringer Ingelheim, Chiesi, EPG Communication Holdings Ltd, FIECON Ltd, Fieldwork International, GlaxoSmithKline, Mylan, Mundipharma, Novartis, OM Pharma SA, PeerVoice, Phadia AB, Spirosure Inc, Strategic North Limited, Synapse Research Management Partners S.L., Talos Health Solutions, Theravance, and WebMD Global LLC; grants and unrestricted funding for investigator-initiated studies (conducted through Observational and Pragmatic Research Institute Pte Ltd) from AstraZeneca, Boehringer Ingelheim, Chiesi, Mylan, Novartis, Regeneron Pharmaceuticals, Respiratory Effectiveness Group, Sanofi Genzyme, Theravance, and UK National Health Service; payment for lectures/speaking engagements from AstraZeneca, Boehringer Ingelheim, Chiesi, Cipla, GlaxoSmithKline, Kyorin, Mylan, Mundipharma, Novartis, Regeneron Pharmaceuticals, and Sanofi Genzyme; payment for travel/ accommodation/meeting expenses from AstraZeneca, Boehringer Ingelheim, Mundipharma, Mylan, Novartis, and Thermofisher; and stock/stock options from AKL Research and Development Ltd, which produces phytopharmaceuticals. He also owns $74 \%$ of the social enterprise Optimum Patient Care Ltd (Australia and UK) and $92.61 \%$ of Observational and Pragmatic Research Institute Pte Ltd (Singapore); has 5\% shareholding in Timestamp, which develops adherence monitoring technology; is a peer reviewer for grant committees of the UK Efficacy and Mechanism Evaluation programme, and Health Technology Assessment; and was an expert witness for GlaxoSmithKline. G. S. D. reports personal fees from Boehringer Ingelheim. H. M. H. has no conflicts of interest to declare. J. H. reports personal fees from AstraZeneca, Boehringer Ingelheim, Chiesi, Cipla, Circassia, and Teva outside the submitted work. M. W. H. serves on the advisory boards of Boehringer Ingelheim and Theravance; reports consulting fees from Olympus Medical; reports non-financial manuscript support from Cactus Communications, and is on the speakers' bureau for Theravance. O. S. U. reports grants and personal fees from AstraZeneca, Boehringer Ingelheim, GlaxoSmithKline, and Chiesi; personal fees from Aerocrine, Napp, Mundipharma, Sandoz, Takeda, Zentiva, Cipla, and Pearl Therapeutics; and grants from Novartis, Philips Respironics, Pieris-AG, Pfizer, Roche, Sandoz, Trudell Medical, UCB, Ventura, Zentive, Prosonix, and Edmond 
Pharma outside the submitted work. The authors report no other conflicts of interest in this work.

\section{References}

1. Laube BL, Janssens HM, de Jongh FHC, et al. What the pulmonary specialist should know about the new inhalation therapies. Eur Respir J. 2011;37(6):1308-1331. doi:10.1183/09031936.00 166410

2. Bonini M, Usmani OS. The importance of inhaler devices in the treatment of COPD. COPD Res Pract. 2015;102(1):10-19. doi:10.1016/j.rmed.2007.07.031

3. Mahler DA. The role of inspiratory flow in selection and use of inhaled therapy for patients with chronic obstructive pulmonary disease. Respir Med. 2020;161:105857. doi:10.1016/j.rmed.2019.105857

4. Lavorini F, Fontana GA, Usmani OS. New inhaler devices - the good, the bad and the ugly. Respiration. 2014;88(1):3-15. doi:10.1159/ 000363390

5. Dalby RN, Eicher J, Zierenberg B. Development of Respimat ${ }^{\circledR}$ Soft Mist ${ }^{\mathrm{TM}}$ Inhaler and its clinical utility in respiratory disorders. Med Devices (Auckl). 2011;4:145-155. doi:10.2147/MDER.S7409

6. Dhand R, Dolovich M, Chipps B, Myers TR, Restrepo R, Farrar JR. The role of nebulized therapy in the management of COPD: evidence and recommendations. COPD. 2012;9(1):58-72. doi:10.3109/ 15412555.2011.630047

7. Azouz W, Chetcuti P, Hosker HSR, Saralaya D, Chrystyn H. Inhalation characteristics of asthma patients, COPD patients and healthy volunteers with the Spiromax ${ }^{\circledR}$ and Turbuhaler $^{\circledR}$ devices: a randomised, cross-over study. BMC Pulm Med. 2015;15:47. doi:10.1186/s12890-015-0043-x

8. Ghosh S, Pleasants RA, Ohar JA, Donohue JF, Drummond MB. Prevalence and factors associated with suboptimal peak inspiratory flow rates in COPD. Int $J$ Chron Obstruct Pulmon Dis. 2019;14:585-595. doi:10.2147/COPD.S195438

9. Mahler DA. Peak inspiratory flow rate: an emerging biomarker in chronic obstructive pulmonary disease. Am J Respir Crit Care Med. 2019;199(12):1577-1579. doi:10.1164/rccm.201901-0005LE

10. Mahler DA. Peak inspiratory flow rate as a criterion for dry powder inhaler use in chronic obstructive pulmonary disease. Ann Am Thorac Soc. 2017;14(7):1103-1107. doi:10.1513/ AnnalsATS.201702-156PS

11. Clark AR, Hollingworth AM. The relationship between powder inhaler resistance and peak inspiratory conditions in healthy volunteers-implications for in vitro testing. J Aerosol Med. 1993;6 (2):99-110. doi:10.1089/jam.1993.6.99

12. Duarte AG, Tung L, Zhang W, Hsu ES, Kuo YF, Sharma G. Spirometry measurement of peak inspiratory flow identifies suboptimal use of dry powder inhalers in ambulatory patients with COPD. Chronic Obstruct Pulmon Dis. 2019;6(3):246-255. doi:10.15326/ jcopdf.6.3.2018.0163

13. Benque B, Khinast JG. Understanding the motion of hard-shell capsules in dry powder inhalers. Int J Pharm. 2019;567:118481. doi:10.1016/j.ijpharm.2019.118481

14. Usmani OS, Lavorini F, Marshall J, et al. Critical inhaler errors in asthma and COPD: a systematic review of impact on health outcomes. Respir Res. 2018;19(1):10. doi:10.1186/s12931-0170710-y

15. Broeders MEAC, Molema J, Hop WCJ, Vermue NA, Folgering HTM. The course of inhalation profiles during an exacerbation of obstructive lung disease. Respir Med. 2004;98 (12):1173-1179. doi:10.1016/j.rmed.2004.04.010

16. Pleasants RA. Dry powder inhalers and humidity: another factor to consider to ensure adequate lung delivery. Ann Am Thorac Soc. 2017;14(10):1602. doi:10.1513/AnnalsATS.201706-454LE
17. Dal Negro RW. Dry powder inhalers and the right things to remember: a concept review. Multidiscip Respir Med. 2015;10(1):13. doi:10.1186/s40248-015-0012-5

18. Capstick TGD, Clifton IJ. Inhaler technique and training in people with chronic obstructive pulmonary disease and asthma. Expert Rev Respir Med. 2012;6(1):91-101; quiz 102-103. doi:10.1586/ ers. 11.89

19. Ghosh S, Ohar JA, Drummond MB. Peak inspiratory flow rate in chronic obstructive pulmonary disease: implications for dry powder inhalers. J Aerosol Med Pulm Drug Deliv. 2017;30(6):381-387. doi:10.1089/jamp.2017.1416

20. Janssens W, VandenBrande P, Hardeman E, et al. Inspiratory flow rates at different levels of resistance in elderly COPD patients. Eur Respir J. 2008;31(1):78-83. doi:10.1183/09031936.00024807

21. Mahler DA, Waterman LA, Gifford AH. Prevalence and COPD phenotype for a suboptimal peak inspiratory flow rate against the simulated resistance of the Diskus ${ }^{\circledR}$ dry powder inhaler. J Aerosol Med Pulm Drug Deliv. 2013;26(3):174-179. doi:10.1089/ jamp.2012.0987

22. Loh CH, Peters SP, Lovings TM, Ohar JA. Suboptimal inspiratory flow rates are associated with chronic obstructive pulmonary disease and all-cause readmissions. Ann Am Thorac Soc. 2017;14 (8):1305-1311. doi:10.1513/AnnalsATS.201611-903OC

23. Sharma G, Mahler DA, Mayorga VM, Deering KL, Harshaw O, Ganapathy V. Prevalence of low peak inspiratory flow rate at discharge in patients hospitalized for COPD exacerbation. Chron Obstruct Pulmon Dis. 2017;4(3):217-224. doi:10.15326/ jcopdf.4.3.2017.0183

24. Jarvis S, Ind PW, Shiner RJ. Inhaled therapy in elderly COPD patients; time for re-evaluation? Age Ageing. 2007;36(2):213-218. doi:10.1093/ageing/afl174

25. Sanders KJC, Kneppers AEM, van de Bool C, Langen RCJ, Schols AMWJ. Cachexia in chronic obstructive pulmonary disease: new insights and therapeutic perspective. $J$ Cachexia Sarcopenia Muscle. 2016;7(1):5-22. doi:10.1002/jcsm. 12062

26. Seheult JN, Costello S, Tee KC, et al. Investigating the relationship between peak inspiratory flow rate and volume of inhalation from a Diskus ${ }^{\mathrm{TM}}$ Inhaler and baseline spirometric parameters: a cross-sectional study. Springerplus. 2014;3:496. doi:10.1186/21931801-3-496

27. Plavec D, Gluncic TJ, Gudelj I, Mise K. [Measurement of inspiratory flow for the selection of the inhalation treatment device for asthma and COPD]. Lijec Vjesn. 2012;134(3-4):84-89. Croatian.

28. Chrystyn H. Is inhalation rate important for a dry powder inhaler? Using the In-Check Dial to identify these rates. Respir Med. 2003;97 (2):181-187. doi:10.1053/rmed.2003.1351

29. Sanders MJ. Guiding inspiratory flow: development of the In-Check DIAL G16, a tool for improving inhaler technique. Pulm Med. 2017;2017:1495867. doi:10.1155/2017/1495867

30. In-Check Dial. How to reset and use the In-Check DIAL: instructions. Alliance Tech Medical. Available from: http://alliance techmedical.com/educationclinicals/. Accessed May 13, 2020.

31. In-Check DIAL G16. Inhaler technique training and assessment tool. Alliance Tech Medical. Available from: http://www.alliancetechmedi cal.com/products/check-dial-training-device/. Accessed May 13, 2020.

32. Abadelah M, Chrystyn H, Larhrib H. Use of inspiratory profiles from patients with chronic obstructive pulmonary disease (COPD) to investigate drug delivery uniformity and aerodynamic dose emission of indacaterol from a capsule based dry powder inhaler. Eur J Pharm Sci. 2019;134:138-144. doi:10.1016/j. ejps.2019.04.018

33. Altman P, Wehbe L, Dederichs J, et al. Comparison of peak inspiratory flow rate via the Breezhaler ${ }^{\circledR}$, Ellipta $^{\circledR}$ and HandiHaler ${ }^{\circledR}$ dry powder inhalers in patients with moderate to very severe COPD: a randomized cross-over trial. BMC Pulm Med. 2018;18(1):100. doi:10.1186/s12890-018-0662-0 
34. Pavkov R, Mueller S, Fiebich K, et al. Characteristics of a capsule based dry powder inhaler for the delivery of indacaterol. Curr Med Res Opin. 2010;26(11):2527-2533. doi:10.1185/03007995.2010.518916

35. Prime D, de Backer W, Hamilton M, et al. Effect of disease severity in asthma and chronic obstructive pulmonary disease on inhalerspecific inhalation profiles through the ELLIPTA ${ }^{\circledR}$ dry powder inhaler. J Aerosol Med Pulm Drug Deliv. 2015;28(6):486-497. doi:10.1089/jamp.2015.1224

36. In-Check Dial G16. Clement Clarke International. Available from: https://www.haag-streit.com/clement-clarke/products/inhalertechnique/in-check-dial-g16/. Accessed May 13, 2020.

37. Drug treatments for asthma and chronic obstructive pulmonary disease that do not use chlorofluorocarbons. U.S. Food and Drug Administration. Available from: https://www.fda.gov/drugs/information-drug-class/drugtreatments-asthma-and-chronic-obstructive-pulmonary-disease-do-notuse-chlorofluorocarbons. Accessed September 7, 2021.

38. FDA approved drugs in pulmonary/respiratory diseases. CenterWatch. Available from: https://www.centerwatch.com/druginformation/fda-approved-drugs/. Accessed May 13, 2019.

39. Prescription and over-the-counter drug product list. 39th edition. Cumulative supplement number 01; January, 2019. Available from: https://www.fda.gov/media/124005/download. Accessed September 7, 2021.

40. Serevent ${ }^{\circledR}$ Diskus ${ }^{\circledR}$ (salmeterol xinafoate) [prescribing information]. North Carolina: GlaxoSmithkline; 2018.

41. Anoro ${ }^{\mathrm{TM}}$ Ellipta $^{\mathrm{TM}}$ (umeclidinium and vilanterol) [prescribing information]. North Carolina: GlaxoSmithkline; 2014.

42. Spiriva ${ }^{\circledR}$ HandiHaler $^{\circledR}$ (tiotropium bromide) [prescribing information]. Connecticut: Boehringer Ingelheim Pharmaceuticals, Inc.; 2015.

43. Utibron ${ }^{\mathrm{TM}}$ Neohaler ${ }^{\circledR}$ (indacaterol and glycopyrrolate) [prescribing information]. Massachusetts: Sunovion Pharmaceuticals Inc.; 2016.

44. Tudorza ${ }^{\circledR}$ Pressair $^{\circledR}$ (Aclidinium bromide) [prescribing information]. Delaware: AstraZeneca Pharmaceuticals LP; 2019.

45. Proair RespiClick ${ }^{\circledR}$ (albuterol sulfate) [prescribing information]. Pennsylvania: Teva Respiratory, LLC; 2015.

46. Proair $^{\circledR}$ Digihaler $^{\mathrm{TM}}$ (albuterol sulfate) [prescribing information]. Pennsylvania: Teva Respiratory, LLC; 2018.

47. Wixela ${ }^{\mathrm{TM}}$ Inhub ${ }^{\mathrm{TM}}$ (fluticasone propionate and salmeterol) [prescribing information]. West Virginia: Mylan Pharmaceuticals Inc.; 2019

48. Alsomali HJ, Vines DL, Stein BD, Becker EA. Evaluating the effectiveness of written dry powder inhaler instructions and health literacy in subjects diagnosed with COPD. Respir Care. 2017;62(2):172-178. doi: $10.4187 /$ respcare 04686

49. Azouz W, Chetcuti P, Hosker HSR, Saralaya D, Stephenson J, Chrystyn H. The inhalation characteristics of patients when they use different dry powder inhalers. J Aerosol Med Pulm Drug Deliv. 2015;28(1):35-42. doi:10.1089/jamp.2013.1119

50. Broeders ME, Molema J, Burnell PK, Folgering HT. Ventolin Diskus and Inspyril Turbuhaler: an in vitro comparison. J Aerosol Med. 2005;18(1):74-82. doi:10.1089/jam.2005.18.74

51. Cegla UH. Pressure and inspiratory flow characteristics of dry powder inhalers. Respir Med. 2004;98(Suppl A):S22-28. doi:10.1016/j. rmed.2004.02.003

52. de Koning JP, van der Mark TW, Coenegracht PMJ, Tromp TFJ, Frijlink HW. Effect of an external resistance to airflow on the inspiratory flow curve. Int $J$ Pharm. 2002;234(1-2):257-266. doi:10.1016/S0378-5173(01)00969-3

53. Farkas A, Szipocs A, Horvath A, et al. Establishment of relationships between native and inhalation device specific spirometric parameters as a step towards patient tailored inhalation device selection. Respir Med. 2019;154:133-140. doi:10.1016/j. rmed.2019.06.021
54. Hira D, Koide H, Nakamura S, et al. Assessment of inhalation flow patterns of soft mist inhaler co-prescribed with dry powder inhaler using inspiratory flow meter for multi inhalation devices. PLoS One. 2018;13(2):e0193082. doi:10.1371/journal.pone.0193082

55. Kawamatawong T, Khiawwan S, Pornsuriyasak P. Peak inspiratory flow rate measurement by using In-Check DIAL for the different inhaler devices in elderly with obstructive airway diseases. $J$ Asthma Allergy. 2017;10:17-21. doi:10.2147/JAA.S127580

56. Magnussen $\mathrm{H}$, Watz $\mathrm{H}$, Zimmermann I, et al. Peak inspiratory flow through the Genuair inhaler in patients with moderate or severe COPD Respir Med. 2009;103(12):1832-1837. doi:10.1016/j.rmed.2009.07.006

57. Mahler DA, Ohar JA, Barnes CN, Moran EJ, Pendyala S, Crater GD. Nebulized versus dry powder long-acting muscarinic antagonist bronchodilators in patients with COPD and suboptimal peak inspiratory flow rate. Chronic Obstruct Pulmon Dis. 2019;6(4):321-331.

58. Mahler DA, Waterman LA, Ward J, Gifford AH. Comparison of dry powder versus nebulized beta-agonist in patients with COPD who have suboptimal peak inspiratory flow rate. J Aerosol Med Pulm Drug Deliv. 2014;27(2):103-109. doi:10.1089/jamp.2013.1038

59. Malmberg LP, Everard ML, Haikarainen J, Lähelmä S. Evaluation of in vitro and in vivo flow rate dependency of budesonide/formoterol Easyhaler ${ }^{\circledR}$. J Aerosol Med Pulm Drug Deliv. 2014;27(5):329-340. doi:10.1089/jamp.2013.1099

60. Malmberg LP, Rytila P, Happonen P, Haahtela T. Inspiratory flows through dry powder inhaler in chronic obstructive pulmonary disease: age and gender rather than severity matters. Int $J$ Chron Obstruct Pulmon Dis. 2010;5:257-262. doi:10.2147/COPD.S11474

61. Melani AS, Bracci LS, Rossi M. Reduced peak inspiratory effort through the Diskus ${ }^{\circledR}$ and the Turbuhaler ${ }^{\circledR}$ due to mishandling is common in clinical practice. Clin Drug Investig. 2005;25 (8):543-549. doi:10.2165/00044011-200525080-00007

62. Negro RD, Micheletto C, Tognella S, Clayton N, Cantini L, Woodcock A. Evidence of adequacy of the performance of the Pulvinal by measuring through-device peak inspiratory flow rate in severe airways obstruction in adults and children. J Aerosol Med. 2001;14(3):343-349. doi:10.1089/089426801316970303

63. Price DB, Yang S, Ming SWY, et al. Physiological predictors Of peak inspiRatory flow using Observed lung function resultS (POROS): evaluation at discharge among patients hospitalized for a COPD exacerbation. Int $J$ Chron Obstruct Pulmon Dis. 2018;13:3937-3946. doi:10.2147/COPD.S174371

64. Quinet P, Young CA, Heritier F. The use of dry powder inhaler devices by elderly patients suffering from chronic obstructive pulmonary disease. Ann Phys Rehabil Med. 2010;53(2):69-76. doi:10.1016/j.rehab.2009.11.001

65. Sarinas PS, Robinson TE, Clark AR, Canfield J Jr, Chitkara RK, Fick RB Jr. Inspiratory flow rate and dynamic lung function in cystic fibrosis and chronic obstructive lung diseases. Chest. 1998;114 (4):988-992. doi:10.1378/chest.114.4.988

66. Seheult JN, O'Connell P, Tee KC, et al. The acoustic features of inhalation can be used to quantify aerosol delivery from a Diskus ${ }^{\mathrm{TM}}$ dry powder inhaler. Pharm Res. 2014;31(10):2735-2747. doi:10.1007/s11095-014-1371-x

67. Terzano C, Oriolo F. Lung characteristics in elderly males and females patients with COPD: differences and optimal use of dry powder inhalers (DPIs). Eur Rev Med Pharmacol Sci. 2017;21 (11):2708-2716.

68. Virchow JC, Weuthen T, Harmer QJ, Jones S. Identifying the features of an easy-to-use and intuitive dry powder inhaler for asthma and chronic obstructive pulmonary disease therapy: results from a 28-day device handling study, and an airflow resistance study. Expert Opin Drug Deliv. 2014;11(12):1849-1857. doi:10.1517/17425247.2014.949236

69. Anderson M, Collison K, Drummond MB, et al. Peak inspiratory flow rate in COPD: an analysis of clinical trial and real-world data. Int J Chron Obstruct Pulmon Dis. 2021;16:933-943. doi:10.2147/ COPD.S291554 
70. Chetta A, Yorgancioglu A, Scuri M, Barile S, Guastalla D, Dekhuijzen PNR. Inspiratory flow profile and usability of the NEXThaler, a multidose dry powder inhaler, in asthma and COPD. BMC Pulm Med. 2021;21(1):65. doi:10.1186/s12890-021-01430-9

71. Jõgi R, Mattila L, Vahteristo M, et al. Inspiratory flow parameters through dry powder inhalers in healthy volunteers and patients with chronic obstructive pulmonary disease (COPD): device resistance does not limit use in COPD. Int J Chron Obstruct Pulmon Dis. 2021;16:1193-1201. doi:10.2147/COPD.S298514

72. Malmberg LP, Pelkonen AS, Vartiainen V, Vahteristo M, Lähelmä S, Jõgi R. Patients with asthma or chronic obstructive pulmonary disease (COPD) can generate sufficient inspiratory flows via Easyhaler ${ }^{\circledR}$ dry powder inhaler: a pooled analysis of two randomized controlled trials. J Thorac Dis. 2021;13(2):621-631. doi:10.21037/jtd-20-2112

73. Chen SY, Huang CK, Peng HC, Yu CJ, Chien JY. Inappropriate peak inspiratory flow rate with dry powder inhaler in chronic obstructive pulmonary disease. Sci Rep. 2020;10(1):7271. doi:10.1038/s41598020-64235-6

74. Ding N, Zhang W, Wang Z, et al. Prevalence and associated factors of suboptimal daily peak inspiratory flow and technique misuse of dry powder inhalers in outpatients with stable chronic airway diseases. Int J Chron Obstruct Pulmon Dis. 2021;16:1913-1924. doi:10.2147/ COPD.S311178

75. Harb HS, Laz NI, Rabea H, Abdelrahim MEA. Prevalence and predictors of suboptimal peak inspiratory flow rate in COPD patients. Eur J Pharm Sci. 2020;147:105298. doi:10.1016/j.ejps.2020.105298

76. Al-Showair RAM, Tarsin WY, Assi KH, Pearson SB, Chrystyn H. Can all patients with COPD use the correct inhalation flow with all inhalers and does training help? Respir Med. 2007;101 (11):2395-2401. doi:10.1016/j.rmed.2007.06.008

77. Broeders ME, Molema J, Vermue NA, Folgering HT. Peak inspiratory flow rate and slope of the inhalation profiles in dry powder inhalers. Eur Respir J. 2001;18(5):780-783. doi:10.1183/ 09031936.01.00240301

78. Broeders MEAC, Molema J, Hop WCJ, Folgering HTM. Inhalation profiles in asthmatics and COPD patients: reproducibility and effect of instruction. J Aerosol Med. 2003;16(2):131-141. doi:10.1089/ 089426803321919898

79. Chodosh S, Flanders JS, Kesten S, Serby CW, Hochrainer D, Witek TJ Jr. Effective delivery of particles with the HandiHaler dry powder inhalation system over a range of chronic obstructive pulmonary disease severity. J Aerosol Med. 2001;14(3):309-315. doi:10.1089/089426801316970268

80. Weiner P, Weiner M. Inspiratory muscle training may increase peak inspiratory flow in chronic obstructive pulmonary disease. Respiration. 2006;73(2):151-156. doi:10.1159/000088095

81. Represas-Represas C, Aballe-Santos L, Fernández-García A, et al. Evaluation of suboptimal peak inspiratory flow in patients with stable COPD. J Clin Med. 2020;9(12):3949. doi:10.3390/jcm9123949

82. Price DB, Roman-Rodriguez M, McQueen RB, et al. Inhaler errors in the CRITIKAL study: type, frequency, and association with asthma outcomes. J Allergy Clin Immunol Pract. 2017;5(4):1071-1081. e1079. doi:10.1016/j.jaip.2017.01.004
83. Sa RC, Zeman KL, Bennett WD, Prisk GK, Darquenne C. Effect of posture on regional deposition of coarse particles in the healthy human lung. J Aerosol Med Pulm Drug Deliv. 2015;28(6):423-431. doi:10.1089/jamp.2014.1189

84. Vytrisalova M, Hendrychova T, Touskova T, et al. Breathing out completely before inhalation: the most problematic step in application technique in patients with non-mild chronic obstructive pulmonary disease. Front Pharmacol. 2019;10:241. doi:10.3389/fphar.2019.00241

85. Bouhuys A. Breathing; Physiology, Environment and Lung Disease. New York: Grune \& Stratton; 1974.

86. Yokoyama H, Yamamura Y, Ozeki T, Iga T, Yamada Y. Analysis of relationship between peak inspiratory flow rate and amount of drug delivered to lungs following inhalation of fluticasone propionate with a Diskhaler. Biol Pharm Bull. 2007;30(1):162-164. doi:10.1248/ bpb.30.162

87. Boshra MS, Almeldien AG, Eldin RS, et al. Inhaled salbutamol from Aerolizer and diskus at different inhalation flows, inhalation volume and number of inhalations in both healthy subjects and COPD patients. Exp Lung Res. 2019;45(3-4):84-91. doi:10.1080/01902148.2019.1621408

88. Boshra MS, Almeldien AG, Salah Eldin R, et al. Total emitted dose of salbutamol sulphate at different inhalation flows and inhalation volumes through different types of dry powder inhalers. Exp Lung Res. 2018;44(4-5):211-216. doi:10.1080/01902148.2018.1489015

89. Barnes CN, Mahler DA, Ohar JA, Lombardi DA, Crater GD. Peak inspiratory flows: defining repeatability limits and a predictive equation for different inhalers. Chest. 2020;158(4):1413-1419. doi:10.1016/j. chest.2020.03.072

90. Hygiene instructions for In Check and In Check DIAL. Alliance Tech Medical; April 13, 2020. Available from: https://www.alliancetechmedi cal.com/files/8915/7443/9937/2019 HYGIENE INSTRUCTIONS FOR_In_Check_and_In_Check_DIAL.pdf. Accessed April 27, 2020.

91. Pulmonary function laboratories: advice regarding COVID-19. American Thoracic Society. Available from: https:/www.thoracic. org/professionals/clinical-resources/disease-related-resources/pulmon ary-function-laboratories.php. Accessed April 27, 2020.

92. Graham BL, Steenbruggen I, Miller MR, et al. Standardization of spirometry 2019 update. An official American Thoracic Society and European Respiratory Society technical statement. Am J Respir Crit Care Med. 2019;200(8):e70-e88. doi:10.1164/rccm.201908-1590ST

93. Culver BH, Graham BL, Coates AL, et al. Recommendations for a standardized pulmonary function report. An official American Thoracic Society technical statement. Am J Respir Crit Care Med. 2017;196(11):1463-1472. doi:10.1164/rccm.201710-1981ST

94. Ruppel GL, Carlin BW, Hart M, Doherty DE. Office spirometry in primary care for the diagnosis and management of COPD: national lung health education program update. Respir Care. 2018;63 (2):242-252. doi:10.4187/respcare.05710

95. Symbicort ${ }^{\circledR}$ (budesonide and formoterol fumarate dihydrate) [prescribing information]. Delaware: AstraZeneca Pharmaceuticals LP; 2006.

96. Stiolto ${ }^{\circledR}$ Respimat $^{\circledR}$ (tiotropium bromide and oladeterol) [prescribing information]. Connecticut: Boehringer Ingelheim Pharmaceuticals, Inc.; 2015

International Journal of Chronic Obstructive Pulmonary Disease

\section{Publish your work in this journal}

The International Journal of COPD is an international, peer-reviewed journal of therapeutics and pharmacology focusing on concise rapid reporting of clinical studies and reviews in COPD. Special focus is given to the pathophysiological processes underlying the disease, intervention programs, patient focused education, and self management protocols. This journal is indexed on PubMed Central, MedLine and CAS. The manuscript management system is completely online and includes a very quick and fair peer-review system, which is all easy to use. Visit http://www.dovepress.com/testimonials.php to read real quotes from published authors. 